\title{
Profile of Pseudomonas aeruginosa in burn infection and their antibiogram study
}

\author{
Haitham M. Al-Habib, Asmaa Z. Al-Gerir, Ansam M. Hamdoon \\ Department of Microbiology, College of Medicine, University of Mosul.
}

(Ann. Coll. Med. Mosul 2011; 37 (1 \& 2): 57-65).

Received: $26^{\text {th }}$ Dec 2010; Accepted: $5^{\text {th }}$ Jun 2011.

\begin{abstract}
Objectives: 1- To evaluate the incidence of Pseudomonas aeruginosa bacterial pathogens in burn patients. 2- To determine the antibiogram profile of Pseudomonas aeruginosa to selected antibacterial agents. 3- To assist their production of $\beta$-lactamases.

Patients and methods: This study enrolled 90 burned patients including $63(70 \%)$ females and 27 $(30 \%)$ males. Pus and wound swabs were collected aseptically from these patients and assessed microbiologically. The isolates of $P$. aeruginosa were tested for their susceptibility to 10 selected antimicrobial agents, and evaluated for $\beta$-lactamases using iodometric and double disk approximation methods.
\end{abstract}

Results: Out of the 90 studied patients with second and third degree burns, 60 (66.7\%) yielded positive bacterial growth, while $30(33.3 \%)$ were culture negative. From the total 105 bacterial isolates $88(83.8 \%)$ were gram negative and the remaining $17(16.2 \%)$ were gram positive. The predominant microorganism was $\mathrm{P}$. aeruginosa $(50 \%)$, whereas the least isolated one was Proteus $(3.3 \%)$. The antibiogram study of $P$. aeruginosa showed that the least resistance was against piperacillin, while the highest resistance was noted in cases of carbencillin and cefoxitin. Multidrug resistance (MDR) $P$. aeruginosa formed $44.4 \%$ of the total isolates of $\mathrm{P}$. aeruginosa and they had statistical association with ceftriaxone, meropenem, ceftazidime and amikacin consumption. Ninety percent of $P$. aeruginosa were $\beta$-lactamases producer and $10 \%$ of them produced the inducible $\beta$-lactamases.

Conclusion: The bacteria isolated from Burn Units are the best examples for the study of pathogenic bacterial species, specially Pseudomonas aeruginosa, other enteric bacilli and Staph. aureus which frequently responsible for human colonization. Also, Pseudomonas aeruginosa and other gram negative bacilli are frequently associated with nosocomial burn infection. Furthermore, most isolates of $P$. aeruginosa from Burn Units are $\beta$ - lactamases producers and most of these isolates were MDR pseudomonas aeruginosa.

الخلاصة

الأهداف: تقييم دور الزو ائف الزراقية والجراثيم الممرضة الأخرى في مرضى الحروق. وكذلك تعيين حساسية جر اثيم

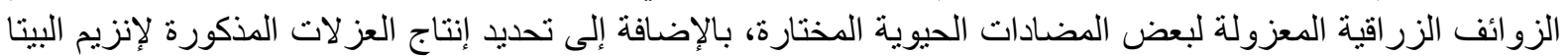
لاكتاميز.

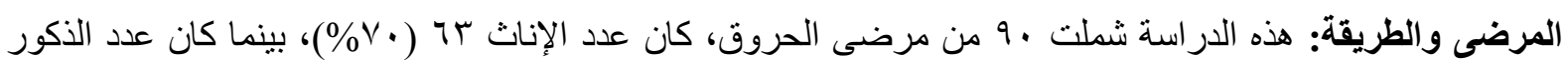

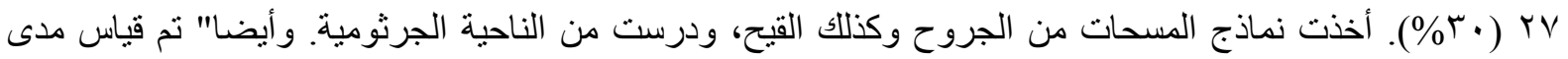

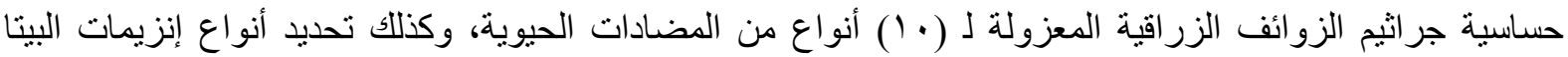
لاكتاميز المنتجة من قبلها باستخدام الطريقة اليودية وطريقة تقريب القرص الثرن الثنائي. 


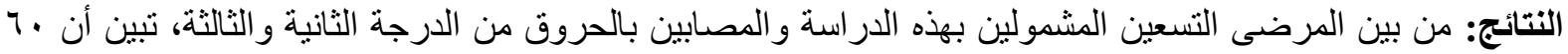

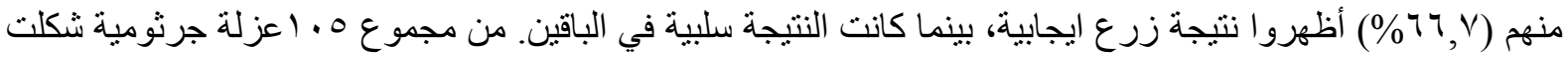

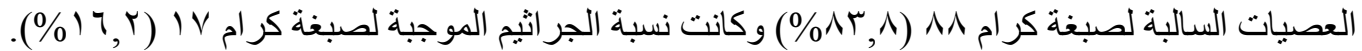

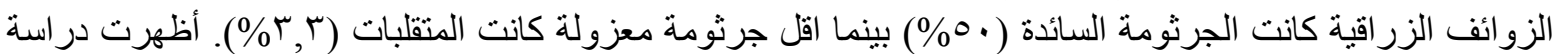

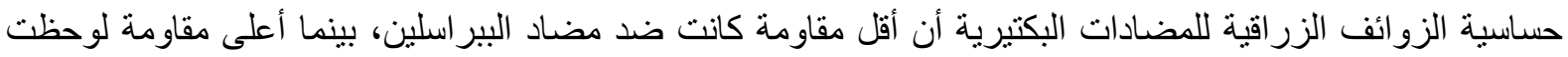

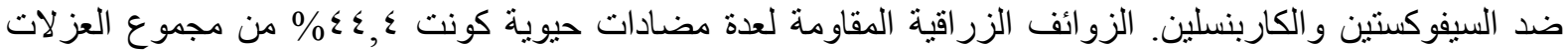

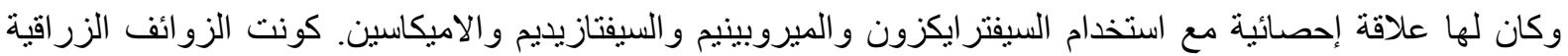

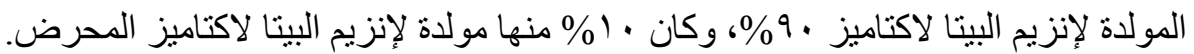

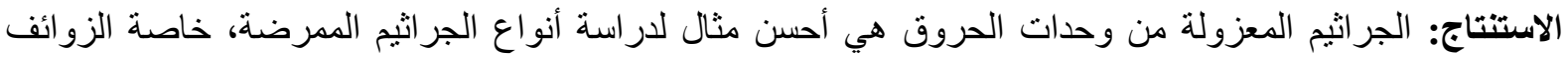

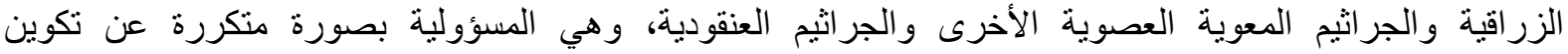

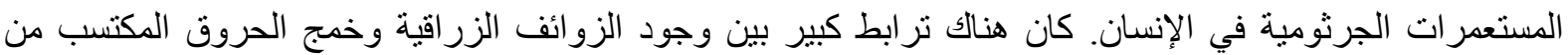

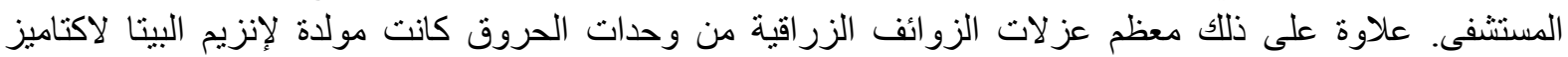
ومعظمها كانت مقاو مة لأكثر من نوع من ملن المضادات الجرثومية.

$\mathrm{T}$ he skin forms a protective barrier against invasion by bacteria, fungi and viruses. Any breach in this barrier provides easy access for microbial invasion. In spite of the enormous advances in medicine and specific treatment of burns, infection continues to pose the greatest danger to burn patients ${ }^{(1)}$. Following the initial period of shock, sepsis is the major complication in burns ${ }^{(2)}$ and it has been estimated that about $75 \%$ of the mortality associated with burn injuries is related to sepsis specially in developing countries ${ }^{(3)}$. In addition, overcrowding in burn units is an important cause of cross-infection ${ }^{(4)}$. Gram positive bacteria from hair follicles and sweat glands colonize the wound within 48 hours of injury ${ }^{(5)}$.

Burn infections are caused by both gram positive and gram negative microorganisms, currently the common pathogens isolated from burn patients are Pseudomonas aeruginosa, Staphylococcus aureus, $\beta$-haemolytic streptococci, Escherichia coli, Klebsiella species and various coliform bacilli. Fungi like Candida albicans and Aspergillus species are also associated with burn infections ${ }^{(6)}$. P. aeruginosa is a gram negative opportunistic pathogen found along with other Pseudomonas species as part of the normal flora of human skin ${ }^{(7)}$. It rarely causes infection in healthy individuals, although it is responsible for serious infections in immunocompromised hosts ${ }^{(8)}$, such as those with severe burn wounds ${ }^{(9)}$, cystic fibrosis patients, cancer patients, and patients with HIV infection ${ }^{(10)}$. Burn causes a breach in the protective skin barrier which suppresses immune system, rendering the patient highly susceptible to infection by P. aeruginosa which then easily colonizes and infects the burn wound ${ }^{(11)}$.

The burn wound is rarely an important health problem, but its infection results in severe complications in patients who sustained burns (12). Infection of burn wounds with P.aeruginosa which disseminates into distant organs via blood stream often leads to bacteremia, endotoxic shock and sepsis ${ }^{(13)}$.

The mortality rate in burn patients who developed septicaemia was greater than $75 \%$ (14). Multidrug resistant bacteria (MDR) have been frequently reported as the cause of nosocomial outbreaks of infections in Burn Units or as wound colonizers in burn patients ${ }^{(15)}$.Multidrug resistant strains of $P$. aeruginosa (resistant to at least three of the following antimicrobials cefotaxime, imipenem, gentamicin and ciprofloxacin) are often isolated among patients suffering from nosocomial infections ${ }^{(16)}$. One of the greatest sources for this resistance is the production of $\beta$-lactamase. The chromosomally encoded Blactamases of Pseudomonas spp. are serine based Ambler class $C$ enzymes (AmpC) 
whose expression is often strictly repressed. The enzyme production can be induced to a high level of expression yielding sufficient enzyme to confer resistance ${ }^{(17)}$. Therefore $\beta$ lactamase detection and identification is valuable ${ }^{(18)}$.

Oral antibiotics are generally ineffective against most serious skin and soft tissue $P$ .aeruginosa infections ${ }^{(14)}$. Treatment of such infections is confounded by the innate and acquired resistance of $P$. aeruginosa to many antibacterial agents ${ }^{(19)}$. Hence the development of new therapeutic and prophylactic agents for the control of bacterial infection in patients with burn wounds is mandatory. An alternative to antibiotic therapy is phage therapy which involves the use of bacterial viruses to target bacterial infections (20)

\section{Aims of the study}

The aims of the current study are to evaluate the incidence of $P$. aeruginosa and bacterial pathogens isolated from burn patients at the Burn Unit in Al-Jumhori Teaching Hospital in Mosul City. Also, to determine the antibiogram profile of the isolated $P$. aeruginosa to some selected antibacterial agents and to evaluate their production of $\beta$-lactamases. This will help to assess the burden of infections at Burn Unit and to formulate antibiotic policy for better management of burn patients.

\section{Patients and methods}

This study was approved by the Scientific Research Committee at the College of Medicine, University of Mosul. Formal consent taken from all patients after clear explanation.

\section{Patients}

This is a prospective study based in the Burn Unit in Al-Jumhori Teaching Hospital in MosulIraq, and the Department of Microbiology, College of Medicine, University of Mosul. The study was conducted during the period from October 2009 to May 2010.

This study enrolled 90 patients admitted to the Burn Unit of whom $27(30 \%)$ were males and $63(70 \%)$ were females (figure 1). The male to female ratio was (1:2.3). The age of the patients ranged from 1-52 (18 $\pm 2 S D)$ years.
Regarding the degree of burn, 21 patients were with second degree burn and 69 patients were with third degree burn.

A history of age, sex, cause, duration at time of study, site, extent of the burn, and the use of antibiotics was taken. None of the patients included in this study had any signs and symptoms of urinary tract infection, blood stream infection, and wound infection based on NNIS system criteria within the first 48 hours after admission.

\section{Microbiological methods}

Clinical specimens used in the current study were pus and wound swabs which were collected aseptically from the patients after bathing on the third day after admission. The specimens were inoculated directly onto $5 \%$ sheep blood agar, nutrient agar and MacConkey's agar which were incubated at $37^{\circ} \mathrm{C}$ for 24 hours, with further 48 hours incubation if there is no growth. Identification of the isolates was relied upon their colonial morphology, gram reaction and standard biochemical tests ${ }^{(21)}$. Further confirmative diagnostic tests for $P$. aeruginosa were attempted including growth at $42^{\circ} \mathrm{C}$ in brain heart infusion, oxidase test, motility test, oxidative-fermentation test for carbohydrate and pigment production.

Pure cultures of the isolates were prepared for further identification and antibiogram study. The isolates were tested for their sensitivity to 10 selected antibiotics which were piperacillin $100 \mathrm{mcg}$, norfloxacin $10 \mathrm{mcg}$, ciprofloxacin $5 \mathrm{mcg}$, gentamicin $10 \mathrm{mcg}$, tobramicin $10 \mathrm{mcg}$, ceftriaxone $30 \mathrm{mcg}$, ticarcillin $75 \mathrm{mcg}$, cefotaxime $10 \mathrm{mcg}$, cefoxitin $30 \mathrm{mcg}$, and carbencillin $100 \mathrm{mcg}$ (Bioanalyse, UK) on Mueller-Hinton (Oxoid UK) using the standard disc diffusion method following NCCLS recommendations ${ }^{(22)}$.

$P$. aeruginosa isolates were also tested for their ability to produce $\beta$-lactamases enzymes using the rapid iodometric method and they were tested for the production of Amp C inducible $\beta$-lactamase by double disc approximation test. In this test, plates were inoculated and cefotaxime $30 \mathrm{mcg}$ and cefoxitin $30 \mathrm{mcg}$ discs were placed $20 \mathrm{~mm}$ apart. B-lactamase inducibility is recognized by 
blunting of the cefotaxime zone adjacent to the cefoxitin disc ${ }^{(17)}$.

The iodometric test: using benzylpencillin in phosphate buffer and bacterial growth from agar is suspended heavily in them. After the addition of starch and iodine, B-lactamase activity is demonstrated by decolorization of iodine within 5 minutes ${ }^{(17)}$.

\section{Statistical analysis}

Z two proportional test was used to evaluate the relationship between the administration of different antibiotics and the isolation of MDR Pseudomonas aeruginosa.

\section{Results}

Among the examined 90 patients with $2^{\text {nd }}$ and $3^{\text {rd }}$ degree burns, $60(66.7 \%)$ of them yielded a positive bacterial growth while 30 (33.3\%) showed a negative growth. Out of the 60 positive cases, pure culture isolation was recovered in $34(56.7 \%)$, while mixed growth was seen in $26(43.3 \%)$. A total of 105 bacterial isolates were detected, most of them $88(83.8 \%)$ were gram negative and the remaining $17(16.2 \%)$ were gram positive (figure 2). The predominant microorganism was P. aeruginosa $(50 \%)$, followed by Klebsiella pneumoniae (26.7\%), Staph. aureus $(11.1 \%)$. E. coli $(10 \%)$, while Acinetobacter and Staph. epidermidis were recovered in similar rate $(7.8 \%)$. The least isolated microogansim was Proteus (3.3\%), as shown in table 1.

Concerning the relation between the depth of burn and the development of sepsis, from the 21 patients with second degree burns $57.1 \%$ were infected. Whereas from the 60 patient with third degree burns, the incidence increased to $69.6 \%$. Such result reflects the importance of burn depth in development of infection.

The antibiogram profile of the isolated $P$. aeruginosa was determined against a panel of antimicrobial agents. Piperacillin showed the lowest resistance rate $(60 \%)$, while the highest resistance was detected against carbencillin and cefoxitin and reached to $96 \%$ of the total isolates (table 2).

In the current study, distribution of $\beta$ lactamases in the isolates of $P$. aeruginosa was $90 \%$. The Amp C inducible $\beta$-lactamase was further investigated and it was found in $10 \%$ of the total isolated $P$. aeruginosa. All P. aeruginosa isolates that produce inducible $\beta$ lactamase were MDR Pseudomonas. MDR Pseudomonas in this study formed 20/45 $(44.4 \%)$ of the isolated $P$. aeruginosa strains. Using two proportional $\mathrm{Z}$ test the relation between MDR $P$. aeruginosa and antibiotic administration was also analyzed. The statistical analysis revealed that there was a significant statistical association between MDR $P$. aeruginosa and the consumption of ceftriaxone $(P \leq 0.006)$, meropenem $(P \leq 0.042)$, ceftazidime $\quad(P \leq 0.001)$ and amikacin $(P \leq 0.014)$, while the intake of other antimicrobial agents was statistically not significant.

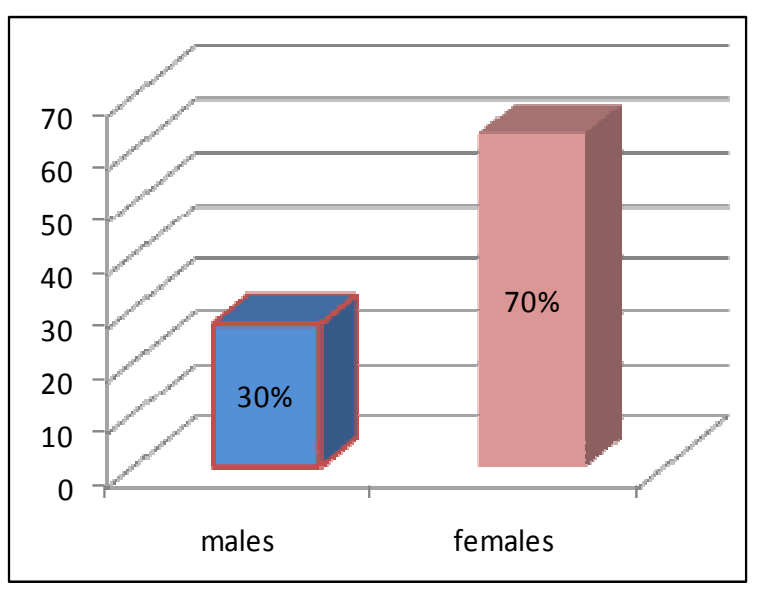

Figure (1): Sex distribution of cases.

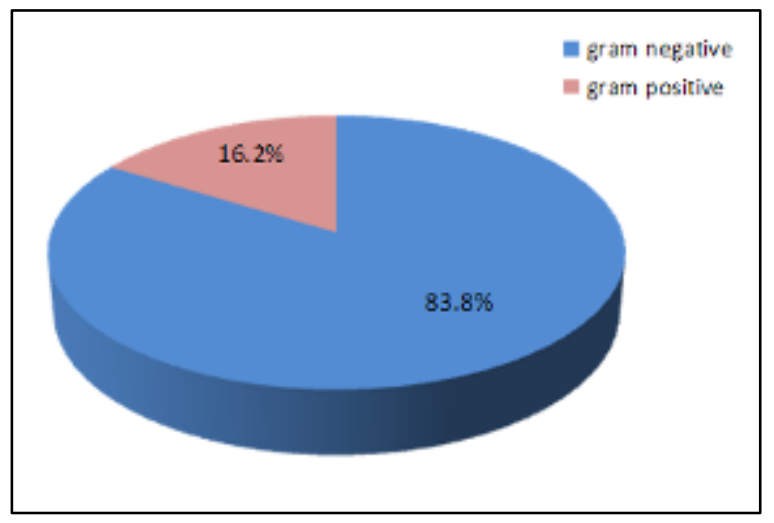

Figure (2): Percentage of gram negative and gram positive isolates from burned patients. 
Table (1): Isolated microorganisms in burn infection.

\begin{tabular}{|l|c|c|c|}
\hline \multicolumn{1}{|c|}{$\begin{array}{c}\text { Type of } \\
\text { bacteria }\end{array}$} & $\begin{array}{c}\text { No. of } \\
\text { isolates }\end{array}$ & $\begin{array}{c}\% \text { from } \\
\text { total } \\
\text { patients }\end{array}$ & $\begin{array}{c}\text { \%from } \\
\text { culture } \\
\text { positive }\end{array}$ \\
\hline P. aeruginosa & 45 & 50 & 75 \\
\hline $\begin{array}{l}\text { Klebsiella } \\
\text { pneumoniae }\end{array}$ & 24 & 26.7 & 40 \\
\hline Staph. aureus & 10 & 11.1 & 16.7 \\
\hline E. coli & 9 & 10 & 15 \\
\hline $\begin{array}{l}\text { Staph. } \\
\text { epidermidis }\end{array}$ & 7 & 7.8 & 11.7 \\
\hline Acinetobacter & 7 & 7.8 & 11.7 \\
\hline Proteus & 3 & 3.3 & 5 \\
\hline Total & 105 & & \\
\hline
\end{tabular}

Table (2): Resistance of Pseudomonas aeruginosa isolates to antibiotics.

\begin{tabular}{|l|c|c|}
\hline \multicolumn{1}{|c|}{ Antibiotics } & Conc. & \% of Resistance \\
\hline Piperacillin & $100 \mathrm{mcg}$ & 60 \\
\hline Norfloxacin & $10 \mathrm{mcg}$ & 73.3 \\
\hline Ciprofloxacin & $5 \mathrm{mcg}$ & 80 \\
\hline Gentamicin & $10 \mathrm{mcg}$ & 86.7 \\
\hline Tobramicin & $10 \mathrm{mcg}$ & 86.7 \\
\hline Ceftriaxone & $30 \mathrm{mcg}$ & 91.1 \\
\hline Ticarcillin & $75 \mathrm{mcg}$ & 93.4 \\
\hline Cefotaxime & $10 \mathrm{mcg}$ & 93.4 \\
\hline Cefoxitin & $30 \mathrm{mcg}$ & 96 \\
\hline Carbencillin & $100 \mathrm{mcg}$ & 96 \\
\hline
\end{tabular}

Table (3): Multidrug resistant Pseudomonas and antibiotic intake.

\begin{tabular}{|l|c|c|c|c|c|}
\hline \multicolumn{1}{|c|}{ Type of antibiotic } & $\begin{array}{c}\text { No. of patients } \\
\text { on antibiotics }\end{array}$ & $\begin{array}{c}\text { No. of patients } \\
\text { showed } \\
\text { pseudomonas } \\
\text { growth(\%) }\end{array}$ & $\begin{array}{c}\text { No. of MDR } \\
\text { Pseudomonas (\%) }\end{array}$ & $\begin{array}{c}\text { \% of MDR } \\
\text { pseudomonas in } \\
\text { patients using } \\
\text { these antibiotics }\end{array}$ & $P_{\text {value* }}^{*}$ \\
\hline $\begin{array}{l}\text { Ampicillin } \\
\text { +cloxacillin }\end{array}$ & 38 & $16(42.1)$ & $13(34.2)$ & 81.25 & 0.477 \\
\hline Ceftriaxone & 21 & $12(57.1)$ & $4(19.04)$ & 33.3 & 0.006 \\
\hline Meropenem & 6 & $4(66.7)$ & $1(16.7)$ & 25 & 0.042 \\
\hline Ciprofloxacin & 6 & $2(33.3)$ & $0(0)$ & 0 & 0.083 \\
\hline Cefotaxime & 6 & $4(66.7)$ & $2(33.3)$ & 50 & 0.221 \\
\hline Ceftazidime & 4 & $3(75)$ & $0(0)$ & 0 & 0.001 \\
\hline Amikacin & 3 & $2(66.7)$ & $0(0)$ & 0 & 0.014 \\
\hline Piperacillin & 5 & $2(40)$ & $0(0)$ & 0 & 0.016 \\
\hline Total & 90 & $45(50)$ & $20(22.2)$ & $44.4 \%$ & \\
\hline
\end{tabular}

${ }^{*} \mathrm{P}$ value: $Z$ two proportion test.

\section{Discussion}

Despite significant improvement in the survival of burn patients, infection complications continue to be the major cause of morbidity and mortality ${ }^{(21)}$. Though control of invasive bacterial burn wound infection, strict isolation techniques and infection control policies have enormously minimized the occurrence of burn wound infection ${ }^{(22)}$. The current study showed a high prevalence of bacterial infections among burned patients which was in agreement with the result of other investigators ${ }^{(23)}$, but in contrast to another study ${ }^{(24)}$. In the present work burn wound swab and pus yielded positive bacterial growth in $66.7 \%$ of examined cases which was similar to the observation of other workers ${ }^{(25,26,27)}$. Solitary isolates were found in $56.7 \%$ of the studied cases which was in accordance with the result reported by Daher et al., who obtained pure culture isolation in $58.7 \%$ of their patients ${ }^{(25)}$, while a higher isolation rate $(89.3 \%)$ was reported by Demarco and Santo ${ }^{(27)}$.

Different types of gram positive and gram negative microorganisms were detected in the current study of which gram negative bacteria 
constituted $(83.8 \%)$, and gram positive ones were $(16.2 \%)$. This finding goes with that of kehinde et al., who mentioned that gram negative bacteria constituted $(72 \%)$ of their isolates (26). However, other investigators reported lower isolation rates which ranged between $33-51.1 \%{ }^{(25,27,28)}$. Furthermore, the frequency of hospital infection by gram negative enteric bacilli specially $P$. aeruginosa has been increased during the last decade. Other studies described $P$. aeruginosa as the common cause of nosocomial burn infection ${ }^{(29)}$. In the current study $P$. aeruginosa was proved to be the major cause in burn patients which constituted $50 \%$ of the total isolates and found in $75 \%$ of culture positive cases. This result was in concinnity with the findings of Song et al., who reported a percentage of $(50 \%){ }^{(28)}$. However, other studies reported a lower prevalence of $\mathrm{P}$. aeruginosa in burn infections ${ }^{(25,29,30)}$, while Mansour and Enayat reported a higher isolation rate $(68.3 \%)^{(31)}$. The second most frequent organism recovered in this work was Klebsiella pneumoniae $(26.7 \%)$, which agrees with the result obtained by Kehinde et al., $(34,3 \%)$, and in contrast with that reported by others $^{(32)}$ who mentioned that Proteus was ranked in the second place. One study ${ }^{(32)}$ reported that Staph. auerus was the commonest microorganism associated with burn injuries which was in contrast to the present result where Staph. auerus came in the third place $(11.1 \%)$ after $P$. aeruginosa and Klebsiella. In addition E. coli recovered from $10 \%$ of the total cases and this rate was similar to that detected by Daher et al., ${ }^{(28)}$. The bacterium Acintobacter was isolated from $7.8 \%$ of the examined patients which was a lower percentage compared to that obtained by others $(13.4 \%){ }^{(28)}$.

The difference in prevalence of bacterial isolates may be attributed to the environmental condition of a specific area and contamination of the burn units.

Due to the increased resistance to various antibiotics and cross infection in the hospital environment there is clear change in the bacterial spectrum. Before few decades the predominant bacteria was Streptococcus which then followed by Staph. aureus, but with the frequent use of topical antibiotics, fungi and viruses become more prevalent. Also, due to the introduction of a wide range of antibiotics, resistant gram negative bacteria become more prevalent. This increased resistance to various antibiotics poses a challenge to Burn Care Units because it reduces the effectiveness of treatment and may increases morbidity and mortality.

In the present work antibiogram study of the isolates revealed that most $P$. aeruginosa isolates were resistant to the antibiotics in common use such as gentamicin, ciprofloxacin and ceftriaxon which are being indiscriminately prescribed as empirical treatment for long time. This high resistance to the above mentioned antibiotics was also noticed by other investigators ${ }^{(16,25)}$. Also, resistance to tobromycin was high $(86.7 \%)$ and this findings goes with that of Strateva et al. ${ }^{(16)}$.

In this study the most effective agent against $P$. aeruginosa was piperacillin which yielded the least resistance percentage $(60 \%)$. This could be explained on the basis that piperacillin is not commonly prescribed against Pseudomonas infection in this locality. However, higher resistance to this drug $(86.2 \%)$ was reported by other investigators ${ }^{(16)}$ where the use of this antibiotic is more frequent in their locality.

Actually the MDR P. aeruginosa is a major problem at the mean time. In the current work, it constituted $44.4 \%$ out of the total recovered $P$. aeruginosa, and this finding was in agreement with Strateva et al., $(49.8 \%)^{(16)}$ although it was higher than that reported by other workers ${ }^{(33)}$. Also, the association between MDR P. aeruginosaa and antimicrobial consumption was analyzed in this study. The statistically significant association was found to be with ceftriaxone, meropenem, ceftazidime and amikacin administration which was in contrast to the study performed by Messadi et al., who found the significant association was with the use of ciprofloxacin (34). This discrepancy in the results may be due to the difference of antibiotics use in different localities. 
Production of the enzymes $\beta$-lactamases is the mechanism by which Pseudomonas resists antibiotics. In the current study, P. aeruginosa isolates were tested for $\beta$-lactamases production using the iodometric method and it was found that $90 \%$ of them showed a positive result, which was in concinnity with that reported by another study ${ }^{(30)}$, Moreover, AmpC inducible $\beta$-lactamase production was detected using the disk approximation test and it was found in only $10 \%$ of the total isolated $P$. aeruginosa. This rate was lower than that determined by other researchers ${ }^{(16)}$, but closely similar to that found by Supriya et al., $(7 \%)^{(35)}$. Furthermore, inducible $\beta$-lactamase producers were MDR, this result reflects the role of inducible $\beta$-lactamase in antibiotic resistance.

This increasing rate of MDR may be attributed to the subinhibitory concentration of antibiotics in vivo due to the administration of an inappropriate dosage of $\beta$ lactam antibiotics, or the regular administration of aminoglycosides in combination with $\beta$ lactam drugs which provide optimal conditions for persistence of MDR $P$. aeruginosa strains. These findings highlighted the need for further attention to disinfect inanimate hospital environment and to control contact between staff and patients in order to limit transfer of $P$. aeruginosa in Burn Units. Moreover, the use of some antimicrobial agents must be restricted due to the existence of high resistance. Also, the use of combined effective antibiotics is recommend.

In conclusion, bacteria isolated from Burn Unit's Patients are the best examples for the study of pathogenic bacterial species, specially $P$. aeruginosa, other enteric bacilli and Staph. aureus which are frequently responsible for human colonization. Also, P. aeruginosa and other gram negative bacilli are frequently associated with nosocomial burn infection. Furthermore, most isolates of $P$. aeruginosa from burn units are $\beta$ - lactamases producers and most of these isolates were MDR Pseudomonas aeruginosa.

\section{References}

1. Ekrami A, Kalantar E. Analysis of the bacterial infections in burn patients at
Taleghani Burn Hospital in Ahvaz, Khuzestan province. Iranian Journal of Clinical Infectious Diseases, 2007;2(1):912.

2. Signori M, Grappolini S, Magliano E et al. Updated evaluation of the activity of antibiotics in a burn center. Burns 1992; 18: 500-3.

3. Vindenes $\mathrm{H}$, Bjerknes $\mathrm{R}$. Microbial colonization of large wounds. Burns 1995;21: $575-579$.

4. Gupta M, Gupta OK, Yadu Vanshi RK, et al. Burn epidemiology: the Pink City scene. Burns 1993;19: 47-51.

5. Liwimbi M, Komolafe I. Epidemiology and bacterial colonization of burn injuries in Blantyre. Malawi Medical Journal 2007; 19(1):25-27.

6. Nudegusio L, Algimantas T, Rytis R, et al. Analysis of burn patients and the isolated pathogens. Lithuanian Surgery 2004; 2(3):190-93.

7. Mooij M, Drenkard E, lamas L, et al. Characterization of the integrated filamentous phage Pf5 and its involvement in small-colony formation. Microbiology 2007; 153, 1790-1798.

8. Bodey G, Bolivar R, Fainstein V, et al. Infections caused by Pseudomonas aeruginosa. Rev Infect Dis 1983; 5: 279313.

9. McVay C, Velasquez S, Fralick J. Phage therapy of Pseudomonas aeruginosa infection in a mouse burn wound model. Antimicrob Agents Chem 2007; 51: 19341938.

10. Kukavica-Ibrulj I, Bragonzi A, Paroni M, et al. In vivo growth of Pseudomonas aeruginosa strains PAO1 and PA14 and the hypervirulent strain LESB58 in a rat model of chronic lung infection. J. Bacteriology, 2008; 190: 2804-2813.

11. DeBoer S, O'Connor A. Pre hospital and emergency department burn care. Crit Care Nurs Clin N Am 2004; 16: 61-7.

12. Zorgani A, Zaidi $M$, Ranka $R$, et al. The pattern and outcome of septicaemia in a burns intensive care unit. Ann Burns and Fire Disasters 2002; 15: 179-82. 
13. Church D, Elsayed S, Reid O, et al. Burn wound infections. Clin Microbiol Rev 2006; 19: 403-434.

14. Dale R, Schnell G, Wong J. Therapeutic efficacy of "Nubiotics" against burn wound infection by Pseudomonas aeruginosa. Antimicrob Agents Chem 2004; 48: 29182923.

15. Agnihotri N, Gupta V and Joshi R. Aerobic bacterial isolates from burn wound infections and their antibiograms; A fiveyear study. Burns 2004;30(3):241-43.

16. Strateva T, Ouzounova- RayKova V, Markova B, et al. Problematic clinical isolates of Pseudomonas aeruginosa from the university hospitals in Sofia, Bulgaria: current status antimicrobial resistance and prevailing resistance mechanisms. J. med. Microbiology 2007;56 :956-963.

17. Collee J, Fraser A, Marimion B, et al. Laboratory control of antimicrobial therapy, Mackie and MacCartney Practical Medical Microbiology (14 ${ }^{\text {th }}$ ed.), 1996; 167-168.

18. Anupuraba S, Bhattacharjee A, Garg A, et al. Antimicrobial susceptibility of Pseudomonas aeruginosa isolated from wound infections. Indian Journal of Dermatology 2006;51(4): 286-288.

19. MacManus A, Mason A, McManus J, et al. Twenty-five year review of Pseudomonas aeruginosa bacteremia in a burn center. Eur J Clin Microbiol, 1985; 4: 219-223.

20. Hanlon G. Bacteriophages: an appraisal of their role in the treatment of bacterial infections. Int $\mathrm{J}$ Antimicrob Agents 2007;30: 118-128.

21. Washington W, Stephen A, William J, et al. Non fermentative gram negative bacilli. Koneman's Color and textbook of diagnostic microbiology (6th ed.), 2006; 303-358.

22. National Committee for Clinical Laboratory standards 2004. Performance standards for antimicrobial susceptibility testing, 14th informational supplement M100-S14. National Committee for Clinical laboratory standards Wayne, Pa.

23. David W, Albert T, Basil A. Infection of burn wounds. In: Bennett J, Brachman P,
Hospital Infections, $4^{\text {th }}$ ed. Philadelphia: Lippincott - Raven 1998; p: 587-601.

24. Amin M, Kalantar E. Bacteriological monitoring of hospital borne septicemia in burn patients in Ahvaz, Iran. Burn Surgical Wound Care 2004; 3: 4-8.

25. Ekrami A, Kalantar E. Bacterial infections in burn patients at a burn hospital in Iran. Indian J Med Res December 2007;126: 541-544.

26. Askarian M, Hossseini R. Incidence and outcome of nosocomial infections in female burn patients in Shiraz, Iran. Am J Infect Control 2004; $32: 25$-8.

27. Daher S, Saraf R, Singh $K$, et al. Microbiological Profile of chronic Burn Wounds among patients Admitted in burn unit. JK science 2007;9(4): 182-185.

28. Kehinde A, Ademola S, Oluwatosin O, et al. Pattern of bacterial pathogens in burn wound infections in Ibadan, Nigeria. Annals of Burn and Fire Disasters 2004:XVII(1).

29. Jefferson $L$, de Macedo $S$, Castro $R$. Sepsis in burn infection Rev. Soc. Bras. Med. Trop 2003; 36 (6).

30. Rastegar A, Alaghehbandan R, Akhlaghi L. Burn wound infection and antimicrobial resistance in Tehran, Iran: An increasing problem. Ann Burn Fire Disasters 2005; 18 : 1115-8.

31. Song $W$, Lee $K M$, Kang $H J$, et al. Microbiological aspects of predominant bacteria isolated from the burn patients in Korea. J. Burns 2001; 27(2) : 136-139.

32. Gad G, El Domany R, Zaki S, et al. Characterization of Pseudomonas aeruginosa isolated from clinical and environmental samples in Minia, Egypt: prevalence, antibiogram and resistance mechanisms. Journal of antimicrobial chemotherapy 2007; 60(5):1010-1017.

33. Mansour A, Klantar E. Bacteriological monitoring of hospital borne septicemia in burn patients in Ahvaz, Iran. J Burns \& Surg. Wound Care 2004;3(1):4.

34. Nudegusio L, Algimantas $T$, Rytis $R$, et al. Analysis of burn patients and the isolated pathogens. Lithuanian Surg. 2004; 2: 1903. 
35. Trouillet J, Vuagnat A, Combes A, et al. Pseudomonas aeruginosa ventilatorassociated pneumonia: comparison of episodes due to piperacillin-resistant versus piperacillin -susceptible organisms. Clin Infect Dis 2002; 34:1047-54.

36. Messadi A, Lamia T, Kamel B, et al. Association between antibiotic use and changes in susceptibility patterns of Pseudomonas aeruginosa in an intensive care burn unit. A 5 year study, 2000-2004. Burns 2008;34 (8): 1098-1102.
37. Upathyay S, Ranjan M, Bahattacharjee A. Presence of different beta lactamases classes among clinical isolatesof Pseudomomas aeruginosa expressing Amp C beta lactamases enzyme. The journal of infection in developing country 2010;4(4): 1-5. 